\section{Embryo research ban causes ructions in West Germany}

\section{Munich}

A BAN on embryo research that would make West Germany one of the most strictly regulated countries in the world is moving closer to realization.

Although the stringency of the ban and the vehemence of its supporters may be peculiar to West Germany, the ethical issues raised by the law - such as its compatibility with the legality of abortion or the question of at what stage an embryo should begin to be shielded by law - are generally applicable.

The Deutsche Forschungsgemeinschaft (DFG) and the Max Planck Society (MPG) continue to oppose a ban, on the grounds that it would close the door on the possibility of therapies for terminal diseases (see Nature 327, 6; 1987).

Nevertheless, the MPG issued a statement on 27 June pledging to "support lawmakers in the process of clarification of the ethical and legal problems" involved. MPG president Heinz Staab promised a "strict prohibition" on any research involving human embryos "capable of development" even in early stages "until the bounds of ethically and legally justifiable" research are established.

The DFG said on the same day that it had never funded a project involving human embryos. Such projects are subject to voluntary guidelines of the Bundesärztekammer (a physicians' professional organization), which has reported no applications pending for embryo research.

An 'Embryo Protection Act' will be introduced into the Bundestag this year by the West German Justice Ministry. The law will prohibit research on human embryos under any circumstances, said Detlev von Bülow of the Justice Ministry.

The law would consider a fertilized human egg cell, from the point of the fusion of sperm and egg nuclei, as "deserving of legal protection". The law also prohibits research on totipotent cells removed at an early enough stage to be able to develop into a human being.

The new law would forbid the creation of human-animal chimaeras, the cloning of human beings from totipotent cells or the manipulation of germline cells -- all of which are specifically opposed by the MPG and other scientific organizations.

Also to be banned is the creation of human embryos purely for the purposes of research, even for "high-level scientific goals" such as the improvement of in vitro fertiliation (IVF) techniques or the potential use of fetal tissue or secretions for therapeutic purposes.

IVF as such will not be banned, but researchers would be forbidden to carry out experiments on or even observations of embryos created for the purpose of implantation if there is even the slightest chance of damaging the embryo. Researchers at the seminar estimated that up to 1,000 children have been born in West Germany using IVF since the techniques became available about five years ago.

Violations would be punishable by up to three years of imprisonment and fines of an undetermined amount. It is this "criminalization" of research that the MPG and DFG oppose. Bundestag member Wolf-Michael Catenhusen (Social Democrat), the chairman of the Research and Technology Committee, mentioned the possibility of amending the Justice

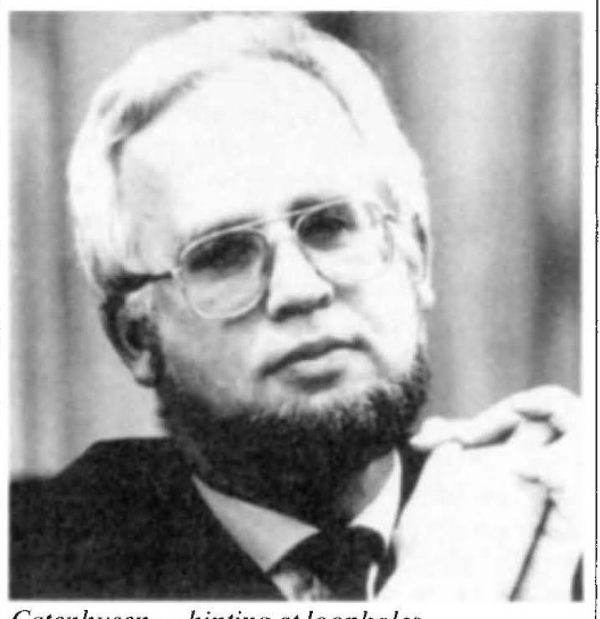
Catenhusen - hinting at loopholes.

Ministry proposal to allow so-called "loopholes" for important research projects.

Seminar participants touched on several ethical questions that underlie the embryo research issue. The strict definition of an embryo was based, said Catenhusen, on the Nuremberg Codex, developed in the wake of the Nazi warcrimes trials, which forbids any experimentation on human beings without the consent of the experimental subject. The moment of fusion was chosen as the dividing line, he said, because, beginning with that moment, a "unique genome arises, which contains all the hereditary material necessary to create a potential human being". Other definitions have been used in other countries (see right).

Researchers who pointed out a logical contradiction in banning embryo research in a country that allows up to 200,000 legal abortions annually were rebuffed by von Bülow and others with two arguments. First, abortion is allowed only under conditions of "social emergency." Second, von Bülow cited a strict ban on embryo research as one way to make people think again about the rights of the embryo in the case of abortion.

\section{International outlook for embryo research \\ Munich}

THE international scene presents a varied picture regarding laws regulating research on human embryos. Albin Eser, a director of the Max Planck Institute for Foreign and International Criminal Law in Freiburg, West Germany, provided most of the information for this roundup.

West Germany is unusual in trying to pass a law concerning embryo research before such research has been done in the country. In the United Kingdom and Australia, the countries where much of the pathfinding research on in vitro fertilization (IVF) was done, medical researchers were allowed to regulate themselves for some years before legislation was considered. The state of Victoria in Australia did not pass a law until 1984 , several years after research with human embryos had begun. The United Kingdom promised a law in 1985 but the issue is due to come before Parliament only this year. Many other countries are considering legislation, Canada, Switzerland, Austria and Sweden among them.

A ban on any type of research on embryos except 'research' which is done for the embryo's benefit seems to be unique to West Germany. Legislation in Australia forbids research on embryos under threat of fines or prison terms except where it has been approved by a central licensing authority. Voluntary guidelines in Switzerland and Great Britain have the same format.

But the situation in both of these countries could change when legislation is passed. Much depends on the definition of an embryo and the stage at which it merits protection under the law.

Countries such as France, which declared in a proposed law in 1984 that the embryo is a "legal subject" from the moment of fertilization, may nevertheless allow some research. Regulations in both France and Great Britain allow embryos to live on in culture past the time when implantation into a woman's uterus is normally carried out. The embryos only live for eight or nine days.

Another point of contention is what may be done with frozen embryos, which can be maintained practically indefinitely in a state of suspended animation. Switzerland's voluntary guidelines forbid freezing any embryos at all, even in the context of IVF therapy. The proposed West German law would not forbid the freezing of 'embryos' up to the point of sperm-egg fusion, but the proposed ban on research would render this procedure superfluous for any end but IVF. Britain and Sweden have tended to allow freezing for later research.
Steven Dickman 